\title{
Variations in Plasma Renin During the Menstrual Cycle
}

\author{
J. J. BROWN,* M.B., B.S., в.SC., M.R.C.P. ; D. L. DAVIES, † M.B., в.S. ; A. F. LEVER,* M.B., B.S., B.SC., M.R.C.P. ; \\ J. I. S. ROBERTSON, $\ddagger$ M.B., B.S., B.SC., M.R.C.P.
}

Brit. med. F., 1964, 2, 1114-1115

Intravenous infusions of renin or angiotensin stimulate aldosterone secretion and excretion (Laragh et al., 1960 ; Genest et al., 1961 ; Carpenter et al., 1961 ; Blair-West et al., 1962). The concentration of renin in plasma varies in several physiological and pathological states (Brown et al., 1964a) in a way which supports the suggestion (Gross, 1958; Davis et al., 1961) that the renin-angiotensin system might regulate aldosterone secretion. As the urinary excretion of aldosterone varies during the menstrual cycle (Reich, 1962 ; Nowaczynski et al., 1962), the present study was undertaken to determine whether these changes might be accompanied by variations in plasma renin.

\section{Methods}

Nine normal nulliparous female medical students (aged 20 to 23) acted as subjects for this study. Records of daily weight and menstrual history were kept for each subject. The timing and occurrence of ovulation were not determined. Diet, fluid intake, and activity were unrestricted. Peripheral blood samples (50 ml.) were taken from each subject at intervals of one week (five subjects) or three days (four subjects) for a period of five weeks. Plasma renin was estimated by an enzyme kinetic method (Lever et al., 1964 ; Brown et al., 1964b).

In the expression of results (see Chart), variations in plasma renin have been calculated as a deviation about the mean value for each subject. For ease of analysis these variations have been arbitrarily grouped into four quarters of the menstrual cycle (the first quarter starting at the first day of menstrual bleeding). Where more than one estimate of plasma renin was made on a subject in a single quarter, the mean value of those results was used.

\section{Results}

Small but consistent variations in plasma renin concentration occurred during the menstrual cycle. Generally the plasma levels were 3 to 5 units per litre lower in the first half of the cycle than in the second (luteal phase). While these changes are significant (difference between the means of second and third quarters $P<0.02$ ), they are small relative to the difference between individual women. In the present experiments individual plasma renin varied between 6.8 and 15.7 units per litre in the first quarter of the menstrual cycle. Larger differences in plasma renin occur in normal subjects as a result of changes in the dietary sodium intake (Brown et al., 1963a, 1964c).

\section{Discussion}

Reich (1962) and Nowaczynski et al. (1962) noted two peaks of aldosterone excretion during the menstrual cycle. The second of these (generally the larger) occurred in the luteal phase of the cycle. If this increase in aldosterone excretion is due to an increase in secretion, it is possible from its timing that it

* Lecturer in Medicine, Medical Unit, St. Mary's Hospital, London. † Pfizer Research Fellow, Medical Unit, St. Mary's Hospital, London. ¥ Senior Lecturer in Therapeutics, Medical Unit, St. Mary's Hospital, London. is attributable to the rise of plasma renin seen in the present study.

A variable gain in weight occurs in the luteal phase of the cycle in some women. Rhodes (1960) discusses the evidence that this might be attributable to the retention of sodium and water. While it is possible that small changes in weight and sodium balance may be mediated by minor variations in renin and aldosterone, we were unable to relate the rise in renin in individual subjects to the small and inconsistent changes in weight which occurred (average increase in luteal phase $1.1 \mathrm{~kg}$.).

The secretion of progesterone rises in the luteal phase of the menstrual cycle (see Carey, 1963, for references). The administration of progesterone is followed by increased sodium excre-

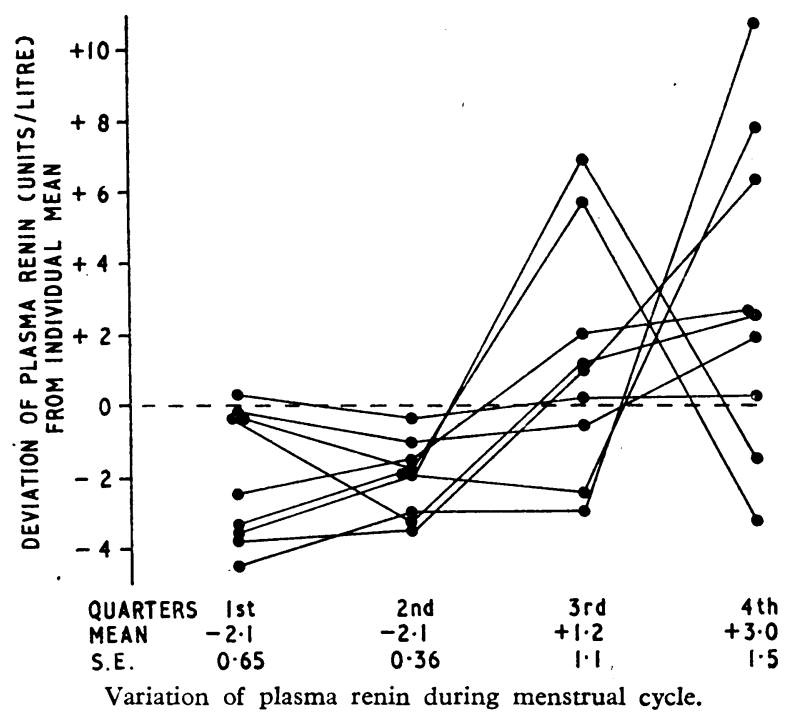

tion (Landau and Lugibihl, 1961), and a rise in both the secretion and the excretion of aldosterone (Laidlaw et al., 1962 ; Glaz and Sugar, 1964). In the majority of subjects in the latter studies the early natriuresis was followed by a rise in aldosterone secretion and excretion and by a period of sodium retention. These changes occurred despite the continued administration of progesterone. As discussed by Laidlaw et al. (1962), the increase in aldosterone could be mediated by the reninangiotensin system. The present finding of a raised plasma renin in the luteal phase of the menstrual cycle is compatible with this suggestion, in that the increased production of progesterone by the corpus luteum might cause a small natriuresis, which could then stimulate the secretion of renin. This in turn would be followed by an increased aldosterone secretion and a period of sodium retention.

We have discussed elsewhere (Brown et al., 1963b) the relation between progesterone, renin, and aldosterone in pregnancy.

\section{Summary}

A small but significant increase in plasma renin occurs in normal women during the luteal phase of the menstrual cycle.

The possible interpretation of this finding is discussed. 
We are grateful to the medical students who acted as the subjects of this study, to Professor W. S. Peart for encouragement, to Mr. M. Tree for technical assistance, and to Mrs. D. M. Roberts for secretarial help.

\section{REFERENCES}

Blair-West, J. R., Coghlan, J. P., Denton, D. A., Goding, J. R., Munro, J. A., Peterson, R. E., and Wintour, M. (1962). F. clin. Invest., 41, 1606 .

Brown, J. J., Davies, D. L., Lever, A. F., Robertson, J. I. S. (1963a). Lancet, 2, 278.

Doak, P. B., Lever, A. F., and Robertson, J. I. S. (1963b). Ibid., 2, 900 .

(1964a). Canad. med. Ass. 7., 90, 201

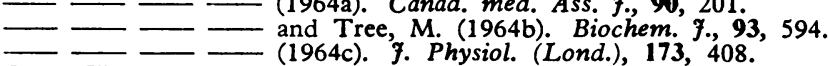

Carey, H. M. (1963). In Modern Trends in Human Reproductive Physiology, edited by H. M. Carey, p. 92. Butterworths, London. Carpenter, C. C. J., Davis, J. O., and Ayers, C. R. (1961). 7. clin.
Invest., 40, 2026.

Davis, J. O., Ayers, C. R., and Carpenter, C. C. J. (1961). Ibid., 40, 1466.

Genest, J., Biron, P., Koiw, E., Nowaczynski, W., Boucher, R., and Chrétien, M. (1961). Ann. intern. Med., 55, 12 .

Glaz, E., and Sugar, K. (1964). Magy. belorv. Arch., 3, 115.

Gross, F. (1958). Klin. W schr., 36, 693.

Laidlaw, J. C., Ruse, J. L., and Gornall, A. G. (1962). F. clin. Endocr., 22, 161 .

Landau, R. L., and Lugibihl, K. (1961). Recent Progr. Hormone Res., $17,249$.

Laragh, J. H., Angers, M., Kelly, W. G., and Lieberman, S. (1960). J. Amer, med. Ass., 174, 234

Lever, A. F., Robertson, J. I. S., and Tree, M. (1964). Biochem. 7., 91 346.

Nowaczynski, W., Koiw, E., Biron, P., Chrétien, M., and Genest, J. (1962). Canad. f. Biochem., 40, 727.

Reich, M. (1962). Aust. Ann. Med., 11, 41.

Rhodes, P. (1960). Fluid Balance in Obstetrics. Lloyd-Luke, London.

\section{Preliminary Communications}

\section{Diagnostic Ovarian Stimulation with Heterologous Gonadotrophin}

Brit. med. F., 1964, 2, 1115-1116

Until recently there was no specific treatment for the majority of women with " no cause" secondary amenorrhoea. After excluding organic causes, the diagnosis usually made was hypothalamic or hypogonadotrophic amenorrhoea. With better prospects of using physiological or pharmacological methods to induce ovulation in such patients, better methods of differential diagnosis, on which suitable treatment may be based, appear necessary.

Using heterologous gonadotrophin extracted from pregnant mares' serum, an ovarian stimulation test has been developed which has proved of assistance in the differential diagnosis of secondary amenorrhoea and in the selection of suitable treatment for such patients. This has permitted limited supplies of human gonadotrophins to be used for treatment rather than diagnosis.

\section{Subjects and Methods}

Twenty-two patients with "no cause" secondary amenorrhoea of at least nine months' duration were initially selected for gonadotrophin stimulation, those with obvious pathological conditions such as Cushing's syndrome or virilizing adrenal hyperplasia being excluded. During preliminary investigations 5 of the 22 patients began to menstruate spontaneously and have continued to do so since. In the remaining 17 the minimum duration of amenorrhoea was nine months, the maximum six years.

Four of these patients had oligomenorrhoea preceding the onset of amenorrhoea and three of the four were mildly hirsute. The onset of amenorrhoea in the remainder was abrupt.

Investigations, including skull and chest $x$-ray examination, full blood count, and assay of 17-oxosteroids and 17-hydroxysteroids, were normal in all patients.

After some preliminary studies it was found that the most satisfactory results could be obtained by collecting 24-hour urine

${ }^{2}$ Details of this method may be obtained from Dr. J. B. Brown, Department of Obstetrics and Gynaecology, University of Melbourne, Carlton N.3, Victoria, Australis. specimens daily for eight days. Oestrone was assayed daily by the unpublished short method of Brown (personal communication, 1961). ${ }^{1}$ The first two days served as controls ; on each of the third, fourth, and fifth days 5,000 units of serum gonadotrophin (Primantron) was given intramuscularly. Urine collections continued for three more days. All of the stimulation tests were carried out in hospital.

\section{RESULTS}

The excretion pattern observed in these 17 patients was clearly of two types.

1. Patients with Polycystic Ovaries.-Four patients polycystic ovaries showed a considerable increase in the excretion of oestrone, excretion after stimulation rising to at least $50 \mu \mathrm{g} . / 24$ hours (Fig. 1).

2. Patients with "Hypothalamic" Amenorrhoea.-The remaining 13 patients showed a significant increase in the

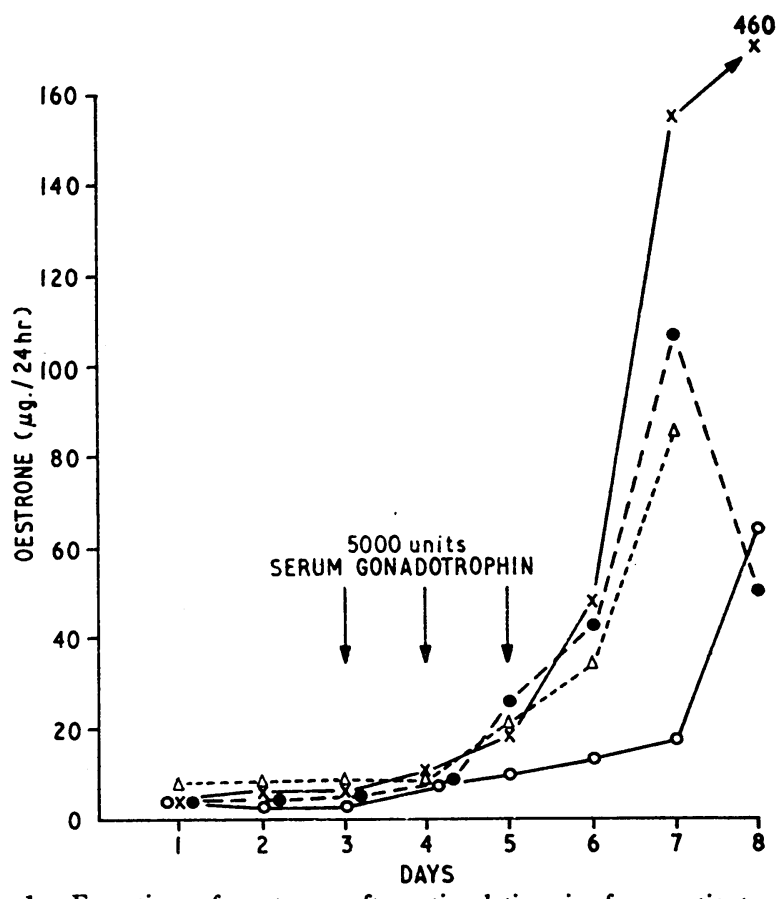

Frg. 1.-Excretion of oestrone after stimulation in four patients with polycystic ovaries. 